\title{
Onset of deglacial warming in West Antarctica driven by local orbital forcing
}

\author{
WAIS Divide Project Members*
}

The cause of warming in the Southern Hemisphere during the most recent deglaciation remains a matter of debate ${ }^{1,2}$. Hypotheses for a Northern Hemisphere trigger, through oceanic redistributions of heat, are based in part on the abrupt onset of warming seen in East Antarctic ice cores and dated to 18,000 years ago, which is several thousand years after high-latitude Northern Hemisphere summer insolation intensity began increasing from its minimum, approximately 24,000 years ago ${ }^{3,4}$. An alternative explanation is that local solar insolation changes cause the Southern Hemisphere to warm independently ${ }^{2,5}$. Here we present results from a new, annually resolved ice-core record from West Antarctica that reconciles these two views. The records show that 18,000 years ago snow accumulation in West Antarctica began increasing, coincident with increasing carbon dioxide concentrations, warming in East Antarctica and cooling in the Northern Hemisphere ${ }^{6}$ associated with an abrupt decrease in Atlantic meridional overturning circulation ${ }^{7}$. However, significant warming in West Antarctica began at least 2,000 years earlier. Circum-Antarctic sea-ice decline, driven by increasing local insolation, is the likely cause of this warming. The marine-influenced West Antarctic records suggest a more active role for the Southern Ocean in the onset of deglaciation than is inferred from ice cores in the East Antarctic interior, which are largely isolated from sea-ice changes.

Exceptional records of Southern Hemisphere climate change come from Antarctic ice cores ${ }^{2,6,7}$. Most of these records are from highaltitude sites on the East Antarctic plateau. Questions about the reliability of the two previous deep West Antarctic ice-core records result in those records often being excluded from reconstructions of Antarctic climate $^{4,8}$. Because the climate of West Antarctica is distinct from that of interior East Antarctica, the exclusion of West Antarctic records may result in an incomplete picture of past Antarctic and Southern Ocean climate change. Interior West Antarctica is lower in elevation and more subject to the influence of marine air masses than interior East Antarctica, which is surrounded by a steep topographic slope ${ }^{9,10}$. Marine-influenced locations are important because they more directly reflect atmospheric conditions resulting from changes in ocean circulation and sea ice. However, ice-core records from coastal sites are often difficult to interpret because of complicated ice-flow and elevation histories. The West Antarctic Ice Sheet (WAIS) Divide ice core (WDC), in central West Antarctica, is unique in coming from a location that has experienced minimal elevation change ${ }^{11}$, is strongly influenced by marine conditions ${ }^{9}$ and has a relatively high snow-accumulation rate, making it possible to obtain an accurately dated record with high temporal resolution.

Drilling of WDC was completed in December 2011 to a depth of $3,405 \mathrm{~m}$. Drilling was halted $\sim 50 \mathrm{~m}$ above the bedrock to avoid contaminating the basal water system. WDC is situated $24 \mathrm{~km}$ west of the Ross-Amundsen ice-flow divide and $160 \mathrm{~km}$ east of the Byrd ice-core site (Supplementary Fig. 1). The elevation is $1,766 \mathrm{~m}$; the present-day snow accumulation rate is $22 \mathrm{~cm} \mathrm{yr}^{-1}$ (ice equivalent) and the average temperature is approximately $-30{ }^{\circ} \mathrm{C}$. The age of the oldest recovered ice is $\sim 68 \mathrm{kyr}$. The WDC06A-7 timescale is based on the identification of annual layers to $29.6 \mathrm{kyr}$ ago using primarily electrical measurements
(Methods). To validate WDC06A-7, we compare times of abrupt changes in atmospheric methane concentration (Supplementary Information) with the Greenland Ice Core Chronology $2005^{12}$ (GICC05). We also compare the methane variations in WDC with abrupt changes in a speleothem $\delta^{18} \mathrm{O}$ record from Hulu Cave, China. The difference in age between the ice and gas at a given depth is calculated using a steadystate firn-densification model and is always less than $500 \mathrm{yr}$. The age differences between WDC06A-7 and GICC05 and between WDC06A-7 and the Hulu Cave timescale are much less than the independent timescale uncertainties (Supplementary Fig. 6)

We interpret $\delta^{18} \mathrm{O}$ of ice (Methods) as annual-mean surface air temperature, as supported by independent estimates of temperature from borehole thermometry ${ }^{13}$. WDC has many similarities with other records (Fig. 1) and resolves Antarctic Isotope Maximum (AIM) events clearly. The late Holocene WDC record shows cooling, suggesting that the increase in $\delta^{18} \mathrm{O}$ at Byrd over the past few thousand years resulted from ice advection and thinning ${ }^{11}$. The abrupt increase in $\delta^{18} \mathrm{O}$ $\sim 22 \mathrm{kyr}$ ago at Siple Dome is not observed at WDC. The AIM1 peak and the subsequent Antarctic Cold Reversal (ACR; 14.5-12.9 kyr ago) are more pronounced in WDC than at Byrd and Siple Dome, possibly owing to discontinuous sampling of the Byrd core and thinning of Siple Dome.

The most rapid warming at WDC occurred after the ACR and culminated at AIM0. The timing of AIM0 is difficult to define because it is composed of two peaks, one $11.95 \mathrm{kyr}$ ago and the other $11.6 \mathrm{kyr}$ ago. The ice accumulation rate at WDC increased abruptly by $37 \%$ in the $400 \mathrm{yr}$ between 12.0 and $11.6 \mathrm{kyr}$ ago (Supplementary Fig. 2). The increase in ice accumulation with little change in $\delta^{18} \mathrm{O}$ shows that the accumulation rate is not controlled strictly by temperature. Abrupt changes in accumulation cannot be recognized in most other Antarctic ice cores because their timescales lack sufficient resolution; it is thus unknown whether this event is specific to WDC or whether accumulation increased abruptly over a larger portion of Antarctica.

The coldest period at WDC was between 28 and $22 \mathrm{kyr}$ ago and was interrupted by AIM2, a 1,000-yr warm period between 24 and 23 kyr ago. AIM2 is also prominent in the EPICA Dronning Maud Land (EDML) ice core $^{7}$ but is muted or nearly absent in other East Antarctic records ${ }^{14}$ (Fig. 1). Other West Antarctic cores also record AIM2, although the low resolution of the Byrd core and the abrupt $\delta^{18} \mathrm{O}$ increase $22 \mathrm{kyr}$ ago in the Siple Dome core have made this feature difficult to discern. AIM2 illustrates the spatial heterogeneity of Antarctic climate variability during the coldest part of the glacial period.

To investigate deglacial warming across the Antarctic continent, we use a sliding Wilcoxon rank-sum test (Fig. 2) to identify times of significant change in the $\delta^{18} \mathrm{O}$ records of WDC, EDML and the EPICA Dome $\mathrm{C}$ ice core ${ }^{6}$ (EDC); we convert the EDC $\delta \mathrm{D}$ record to $\delta^{18} \mathrm{O}$ using $\delta^{18} \mathrm{O}=(\delta \mathrm{D}-10) / 8$. The WDC and EDC timescales can be aligned at a $\sim 150$-yr-long acid deposition event ${ }^{15,16}$, which eliminates the relative age uncertainty at $18 \mathrm{kyr}$ ago. The rank sum test reveals three important features: gradual deglacial warming at WDC was punctuated by periods of more rapid change; the most abrupt warming 


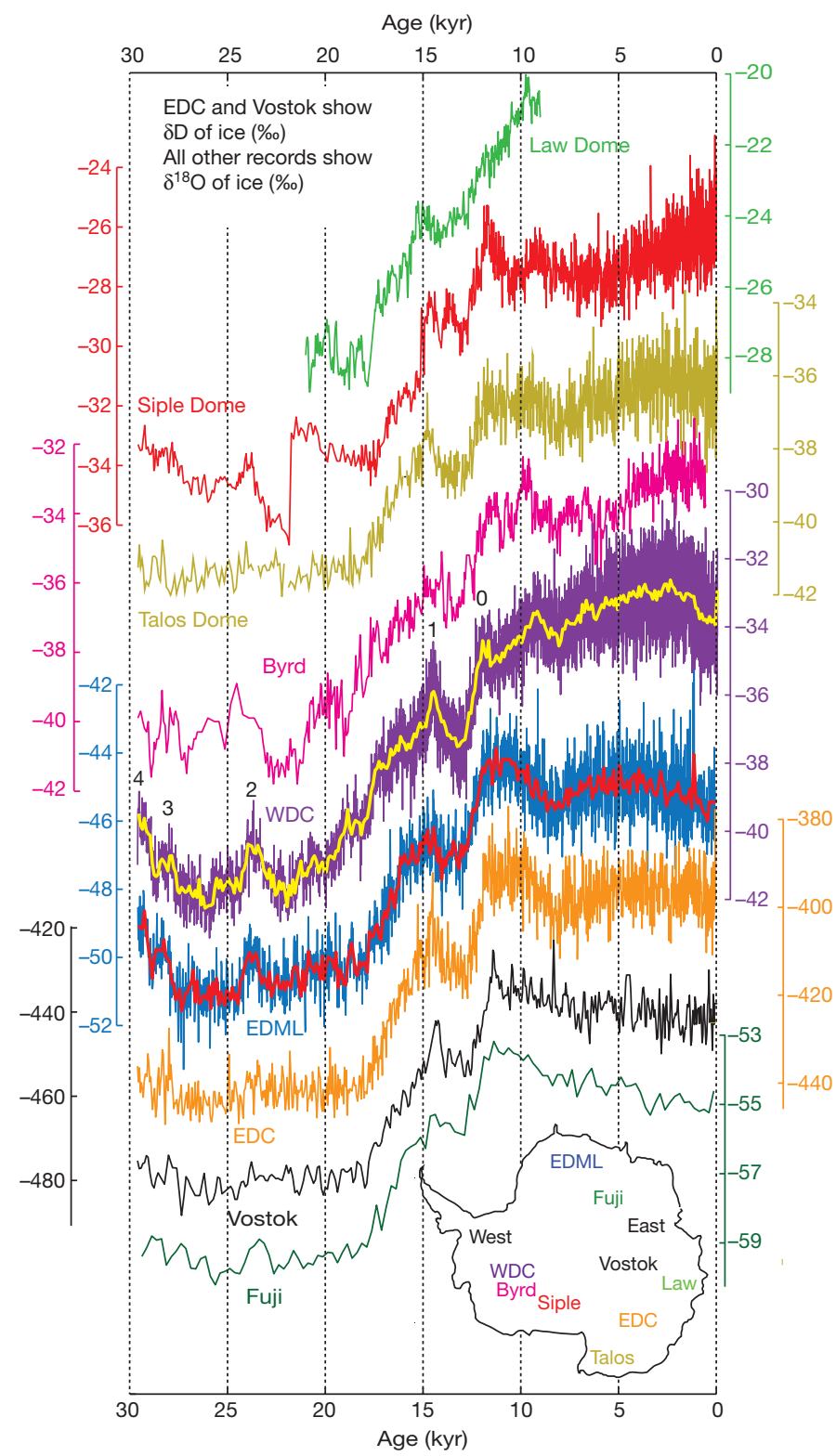

Figure $1 \mid$ Antarctic Isotope Records. Water isotope ratios from nine Antarctic ice cores. Inset, outline of Antarctica with the ice-core locations: Law Dome $^{27}$ (light green), Siple Dome ${ }^{28}$ (red), Byrd ${ }^{29}$ (pink), Talos Dome ${ }^{14}$ (khaki), WDC (purple, WDC06A-7 timescale), EDML 7 (blue), EDC ${ }^{6}$ (orange), Dome Fuji $^{2}$ (dark green), Vostok ${ }^{30}$ (black). Taylor Dome is not plotted because of timescale uncertainties. All records are at original resolution. Thick lines for WDC and EDML are 50-yr averages. EDML, EDC and Vostok use the Lemieux-Dudon ${ }^{31}$ timescale. Numbers above the WDC curve indicate AIM events. $\left(\delta^{18} \mathrm{O}=\left({ }^{18} \mathrm{O} /{ }^{16} \mathrm{O}\right)_{\text {sample }} /\left({ }^{18} \mathrm{O} /{ }^{16} \mathrm{O}\right)_{\text {VSMOW }}-1\right.$ and $\left.\left.\delta \mathrm{D}=\left({ }^{2} \mathrm{H} /{ }^{1} \mathrm{H}\right)_{\text {sample }} /\left({ }^{2} \mathrm{H} /{ }^{1} \mathrm{H}\right)_{\text {Vsmow }}-1\right).\right)$

began at the 18-kyr-ago acid deposition event; and significant warming at WDC began by $20 \mathrm{kyr}$ ago, at least 2,000 yr before significant warming at EDML and EDC.

Further insight into deglacial warming at WDC is gained by investigating the sea-salt sodium (ssNa) record (Methods). Debate remains about whether ssNa on millennial timescales reflects primarily sea-ice production or the strength of atmospheric circulation ${ }^{17}$. In the Amundsen and Ross seas, changes in sea ice and atmospheric circulation are coupled because atmospheric forcing is the dominant control on seaice concentration ${ }^{18}$. We interpret ssNa as a proxy for sea-ice extent and a marker of marine changes (Supplementary Information). The ranksum test reveals that each rapid increase in $\delta^{18} \mathrm{O}$, indicating warming, was accompanied by a decrease in ssNa, suggesting less sea ice (Fig. 2).

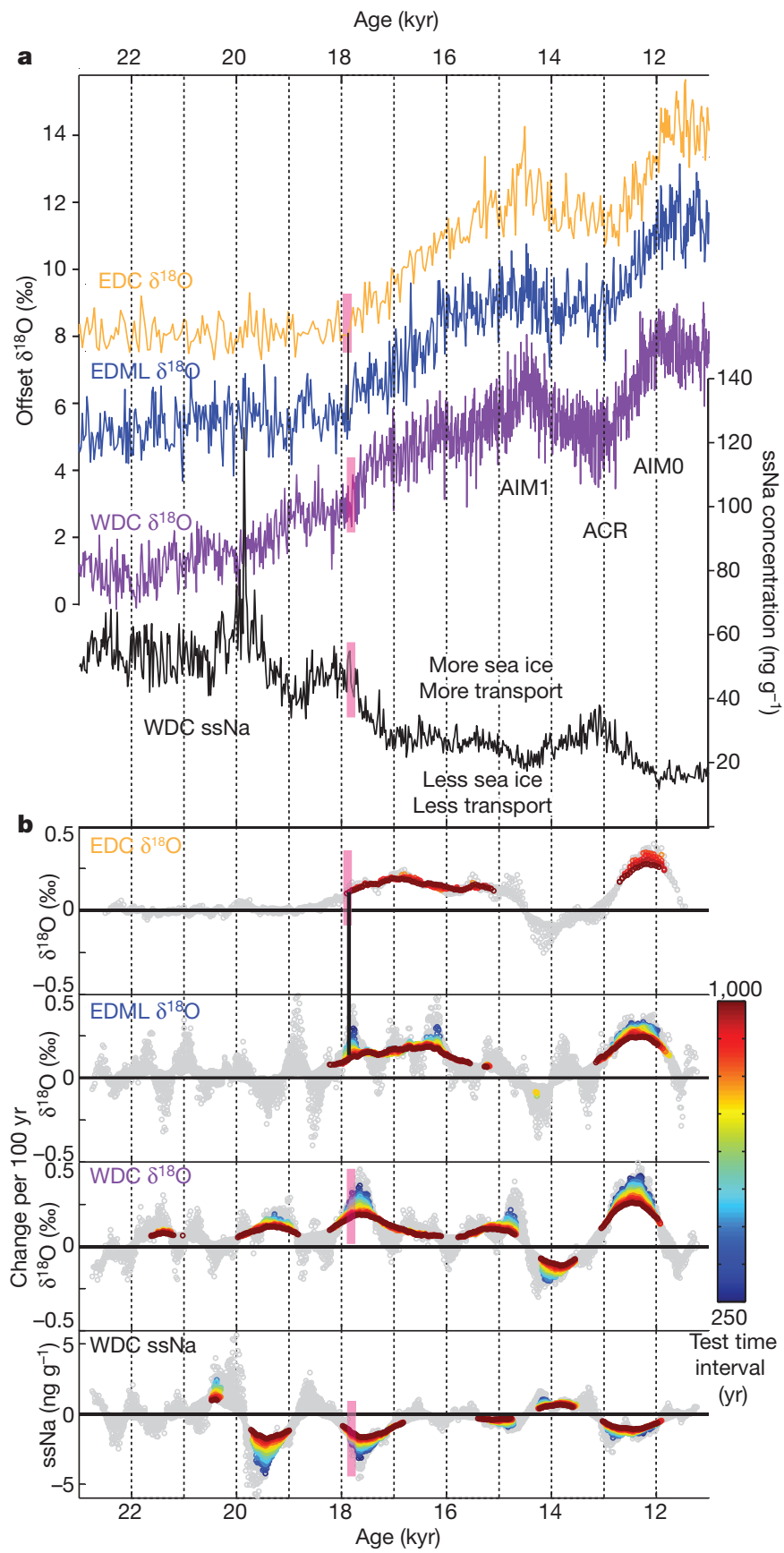

Figure $2 \mid$ Timing of rapid change in Antarctica. a, Water isotope ratios $\left(\delta^{18} \mathrm{O}\right.$, purple) and ssNa concentrations (black) from WDC on WDC06A-7. $\operatorname{EDML}^{7}$ (blue) and $\mathrm{EDC}^{6}$ (orange) $\delta^{18} \mathrm{O}$ use the Lemieux-Dudon ${ }^{31}$ timescale. Constants have been subtracted from $\delta^{18} \mathrm{O}$ records for plotting. Magenta boxes indicate a 150-yr acid deposition event; the black line between EDC and EDML is a volcanic tie point (Methods). ssNa is plotted as 25 -yr median values. b, Rate of change for $\delta^{18} \mathrm{O}$ at WDC, EDML, and EDC and ssNa at WDC. A Wilcoxon rank-sum test (Methods) is used to determine significance. Significant rates of change are coloured by test time interval; rates of change that are not significant are coloured grey.

Consistent with this, the decrease in $\delta^{18} \mathrm{O}$ during the ACR was accompanied by an increase in ssNa.

The accumulation rate at WDC was inferred without assuming a relationship with $\delta^{18} \mathrm{O}$ or temperature (Methods). Although uncertainty in the annual-layer interpretation and ice-flow history used to determine the accumulation rate precludes a statistical assessment comparable to that used for the $\delta^{18} \mathrm{O}$ and ss $\mathrm{Na}$ records, results suggest that an initial increase in accumulation occurred between 18.5 and 
$17 \mathrm{kyr}$ ago (Fig. 3), consistent with the rapid warming $18 \mathrm{kyr}$ ago. This also coincides with evidence for changes in Southern Ocean upwelling ${ }^{19}$, atmospheric carbon dioxide concentration ${ }^{8,20}$ and Atlantic meridional overturning circulation $^{5}$ (AMOC). The accumulation increase probably results from more frequent or stronger moisture-bearing storms penetrating into West Antarctica. This supports a southward shift ${ }^{21}$ or intensification ${ }^{22}$ of the mid-latitude westerly storm track, and is consistent with the hypothesis of a decrease in AMOC leading to Southern Hemisphere warming and Northern Hemisphere cooling ${ }^{3}$ the 'bipolar seesaw'.

Both the WDC and the lower-resolution Byrd ice-core records show that warming in West Antarctica began before the decrease in AMOC that has been invoked to explain Southern Hemisphere warming ${ }^{4,19}$. The most significant early warming at WDC occurred between 20 and $18.8 \mathrm{kyr}$ ago, although a period of significant warming also occurred between 22 and $21.5 \mathrm{kyr}$ ago. The magnitude of the warming at WDC before $18 \mathrm{kyr}$ ago is much greater than at EDML or EDC; linear regression of $\delta^{18} \mathrm{O}$ between 22 and $18 \mathrm{kyr}$ ago shows that it increased by

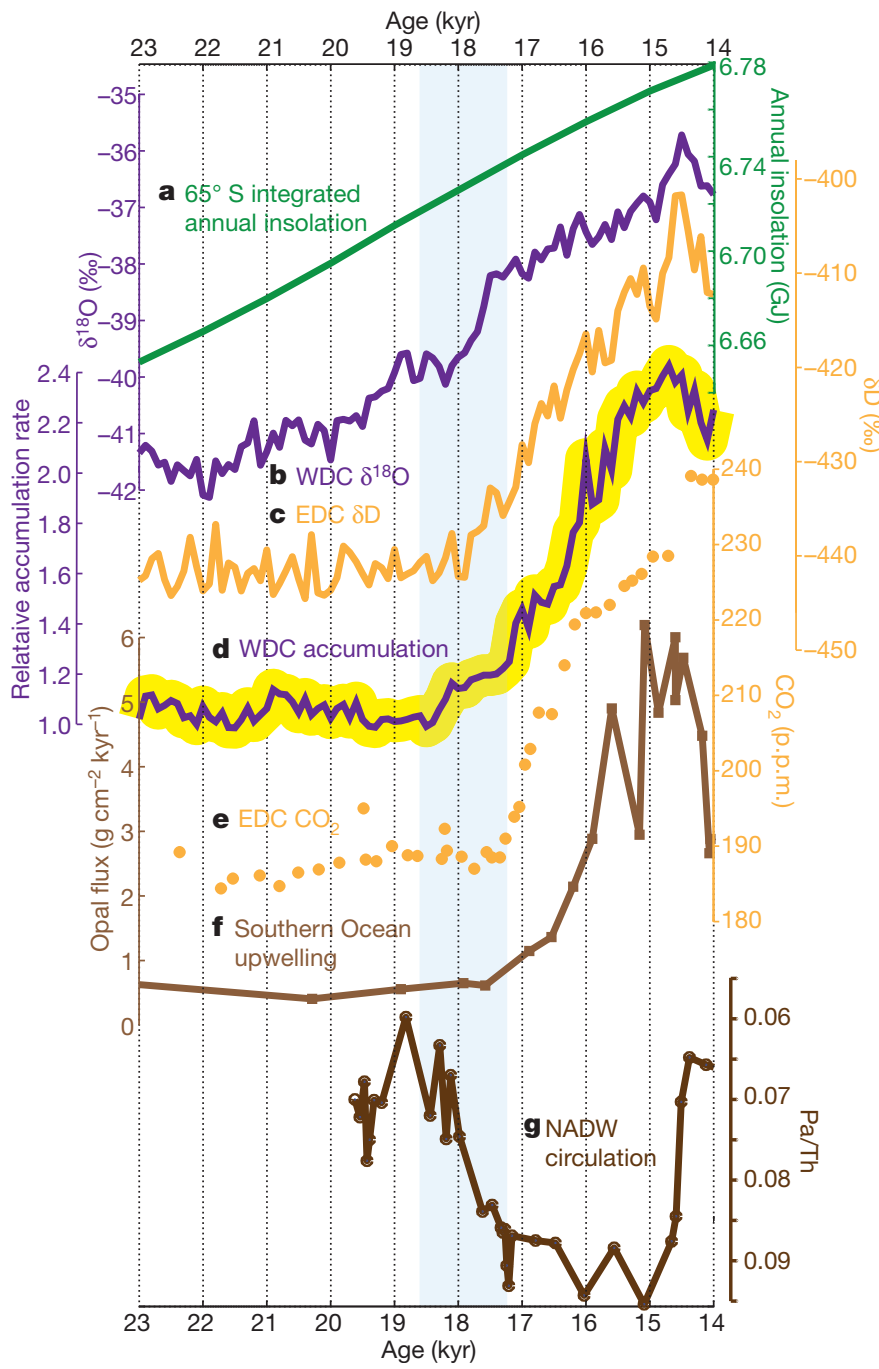

Figure $3 \mid$ Global records of deglaciation. a, Integrated annual insolation at latitude $65^{\circ} \mathrm{S}$. b, 100-yr averages of $\delta^{18} \mathrm{O}$ at WDC on WDC06A-7. c, 100-yr averages of $\delta \mathrm{D}$ at $\mathrm{EDC}^{6}$ on the Lemieux-Dudon ${ }^{31}$ timescale. d, Relative accumulation rate (normalized to the mean value between 19.5 and $18.5 \mathrm{kyr}$ ago) at WDC. Yellow shading is the uncertainty in identifying annual layers (Methods). e, Atmospheric $\mathrm{CO}_{2}$ concentration ${ }^{20}$ from EDC on the LemieuxDudon $^{31}$ timescale.f, Opal flux ${ }^{19}$, a proxy for upwelling, from ocean sediment core TNO57-13-4PC in the South Atlantic. g, Pa/Th, a proxy for North Atlantic Deep Water (NADW) circulation ${ }^{5}$, from sediment core GCC5. Blue shading indicates a period with relatively abrupt changes in all palaeoclimate records $(\mathbf{b}-\mathbf{g})$.
$2.2 \%$ at WDC, by $0.4 \%$ at EDML and by $0.1 \%$ at EDC (Fig. 2 ). It is very unlikely that the $2.2 \%$ increase at WDC can be attributed to elevation change; this magnitude of isotope change would require more than $200 \mathrm{~m}$ of ice-sheet thinning, twice the amount of thinning that occurred during the Holocene epoch when the grounding line retreated hundreds of kilometres (Supplementary Information). The subdued warming at EDML and the lack of warming at EDC are consistent with the lack of clear AIM2 signals in some East Antarctic cores, and suggest that cores from the East Antarctic plateau do not capture the full magnitude of Southern Hemisphere climate variability.

There is evidence that warming at WDC before $18 \mathrm{kyr}$ ago is due to decreasing sea ice. The ssNa at WDC began to decrease $20 \mathrm{kyr}$ ago, probably as a result of both decreasing sea-ice extent and decreasing strength of transport from changes in atmospheric circulation. A marine record from the southwest Atlantic Ocean indicates that significant summer and winter sea-ice retreat began before $22 \mathrm{kyr} \mathrm{ago}^{23}$. Furthermore, a reduction in sea-ice extent can explain the different magnitude of warming among ice-core sites before $18 \mathrm{kyr}$ ago. The high East Antarctic plateau is largely isolated from coastal changes because the local marine air masses do not have the energy to rise above the steep coastal escarpment ${ }^{10}$.

To illustrate the variable sensitivity of different areas in Antarctica to changes in sea-ice extent, we used an atmospheric general circulation model $^{24}$. Using Last Glacial Maximum (LGM) sea surface temperature and sea-ice boundary conditions from a fully coupled model run ${ }^{25}$, we performed a control run of the ECHAM4.6 atmospheric model with the LGM sea-ice extent and a comparison run with reduced sea-ice extent (Supplementary Information). Sea surface temperatures are prescribed; the atmospheric circulation therefore responds to the change in sea-ice extent but the sea-ice extent is not further affected by the changes in atmospheric circulation. The magnitude of sea-ice retreat is consistent with evidence for reduced sea ice in the southwest Atlantic between 22 and $18 \mathrm{kyr}$ ago $^{23}$. In response to the sea-ice retreat, all of West Antarctica and coastal East Antarctica is enriched in precipitation-weighted $\delta^{18} \mathrm{O}$, whereas interior East Antarctica is little changed or is depleted (Fig. 4). The positive $\delta^{18} \mathrm{O}$ anomalies probably extend unrealistically far into the East Antarctic interior because of the low-resolution topography in the climate model. Although the details of the spatial pattern of $\delta^{18} \mathrm{O}$ anomalies are dependent on model resolution and on the specified boundary conditions, the greater

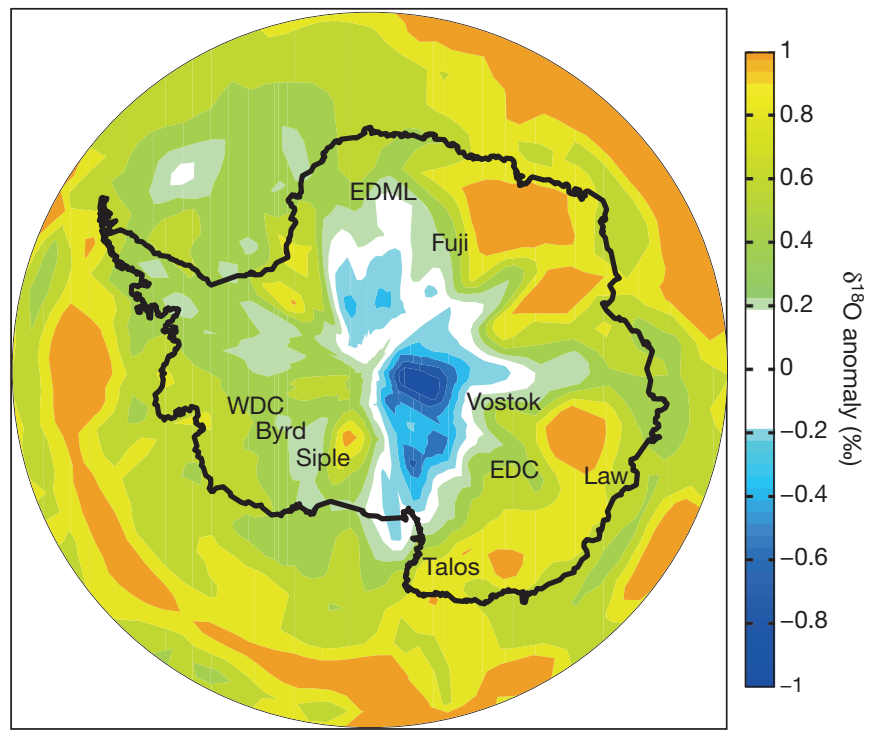

Figure $4 \mid$ Antarctic $\delta^{18} \mathrm{O}$ response to sea-ice decrease. Response of precipitation-weighted $\delta^{18} \mathrm{O}$ to an approximately zonally symmetric southward displacement of the sea-ice edge (Supplementary Fig. 9) in the ECHAM4.6 climate model run with LGM boundary conditions. 
sensitivity of the WAIS Divide region to sea-ice decline compared with locations in interior East Antarctica is clear.

Local orbital forcing is a likely cause of the inferred sea-ice change. Integrated annual insolation at latitude $65^{\circ} \mathrm{S}$ increased by $1 \%$ between 22 and $18 \mathrm{kyr}$ ago. The additional annual insolation is $60 \mathrm{MJ} \mathrm{m}^{-2}$, which is enough to melt $5 \mathrm{~cm} \mathrm{~m}^{-2}$ of sea ice assuming an albedo of 0.75 . The increase in integrated summer insolation, where summer is defined as days with insolation above a threshold ${ }^{26}$ of $275 \mathrm{~W} \mathrm{~m}^{-2}$, is greater than the total annual increase (Supplementary Fig. 10). Thus, the increase comes in summer, when it is most likely to be absorbed by low-albedo open water. The summer duration also begins increasing at $23 \mathrm{kyr}$ ago; longer summers and shorter winters may also contribute to the decrease in sea-ice extent ${ }^{1}$. The effect of an increase in insolation would be amplified by the sea-ice/albedo feedback.

The abrupt onset of East Antarctic warming ${ }^{4,8}$, increasing $\mathrm{CO}_{2}$ (ref. 20) and decreasing $\mathrm{AMOC}^{5} 18 \mathrm{kyr}$ ago has supported the view that deglaciation in the Southern Hemisphere is primarily a response to changes in the Northern Hemisphere ${ }^{3}$. Yet the evidence of warming in West Antarctica and corresponding evidence for sea-ice decline in the southeast Atlantic $\mathrm{c}^{23}$ show that climate changes were ongoing in the Southern Ocean before 18 kyr ago, supporting an important role for local orbital forcing ${ }^{1}$. Warming in the high latitudes of both hemispheres before $18 \mathrm{kyr}$ ago implies little change in the interhemispheric temperature gradient that largely determines the position of the intertropical convergence zone and the position and intensity of the mid-latitude westerlies ${ }^{21,22}$. We propose that when Northern Hemisphere cooling occurred $\sim 18 \mathrm{kyr}$ ago, coupled with an already-warming Southern Hemisphere, the intertropical convergence zone and mid-latitude westerlies shifted southwards in response. The increased wind stress in the Southern Ocean drove upwelling, venting of $\mathrm{CO}_{2}$ from the deep ocean ${ }^{19}$ and warming in both West Antarctica and East Antarctica. The new WDC record thus reveals an active role for the Southern Hemisphere in initiating global deglaciation.

\section{METHODS SUMMARY}

The WDC06A-7 timescale is based on measurements of sulphur, sodium, black carbon and electrical conductivity above $577 \mathrm{~m}$ (to 2,358 yr before AD 1950), and primarily on electrical measurements below $577 \mathrm{~m}$. Using atmospheric methane as a stratigraphic marker, WDC06A-7 and GICC05 agree to within $100 \pm 200 \mathrm{yr}$ at the three abrupt changes between 14.7 and $11.7 \mathrm{kyr}$ ago; WDC06A-7 is older by $500 \pm 600 \mathrm{yr}$ at $24 \mathrm{kyr}$ ago, by $250 \pm 300 \mathrm{yr}$ at $28 \mathrm{kyr}$ ago and by $350 \pm 250 \mathrm{yr}$ at 29 kyr ago (Supplementary Fig. 6). WDC06A-7 agrees within the uncertainties with the Hulu Cave timescale and is older by $50 \pm 300 \mathrm{yr}$ at $28 \mathrm{kyr}$ ago and by $100 \pm 300 \mathrm{yr}$ at $29 \mathrm{kyr}$ ago.

We measured $\delta^{18} \mathrm{O}$ at a resolution of $0.5 \mathrm{~m}$ using laser spectroscopy with calibration to Vienna Standard Mean Ocean Water (VSMOW). We report ssNa concentration rather than flux because wet deposition dominates at higher accumulation rates. The accumulation-rate record was derived independently from the stable-isotope record using a one-dimensional ice-flow model to calculate the thinning function.

Periods of significant change in $\delta^{18} \mathrm{O}$ and ss $\mathrm{Na}$ are identified with a sliding, nonparametric Wilcoxon rank-sum test. The data were averaged to 25 -yr resolution for WDC and EDML, and to 50-yr resolution for EDC. We tested pairs of adjacent blocks of data against the null hypothesis of equal medians, performing the test at all points along the record. We assessed change on multiple timescales using a range of block sizes corresponding to time intervals of 250-1,000 yr for WDC and EDML and 500-1,000 yr for EDC. We used an effective 95\% a-posteriori confidence requirement; the critical significance level $(p)$ was determined as $1-0.95^{1 / N}$ where $N$ is the number of test realizations.

We used the ECHAM4.6 atmospheric general circulation model at T42 resolution $\left(2.8^{\circ}\right.$ by $\left.2.8^{\circ}\right)$ with 19 vertical levels and glacial sea surface temperature boundary conditions.

Full Methods and any associated references are available in the online version of the paper.

Received 4 January; accepted 12 June 2013.

Published online 14 August 2013.

1. Huybers, P. \& Denton, G. Antarctic temperature at orbital timescales controlled by local summer duration. Nature Geosci. 1, 787-792 (2008).
2. Kawamura, K. et al. Northern Hemisphere forcing of climatic cycles in Antarctica over the past 360,000 years. Nature 448, 912-916 (2007).

3. Clark, P. U., Pisias, N. G., Stocker, T. F. \& Weaver, A. J. The role of the thermohaline circulation in abrupt climate change. Nature 415, 863-869 (2002).

4. Shakun, J. D. et al. Global warming preceded by increasing carbon dioxide concentrations during the last deglaciation. Nature 484, 49-54 (2012).

5. McManus, J. F., Francois, R., Gherardi, J. M., Keigwin, L. D. \& Brown-Leger, S. Collapse and rapid resumption of Atlantic meridional circulation linked to deglacial climate changes. Nature 428, 834-837 (2004).

6. EPICA community members. Eight glacial cycles from an Antarctic ice core. Nature 429, 623-628 (2004).

7. EPICA. Community Members. One-to-one coupling of glacial climate variability in Greenland and Antarctica. Nature 444, 195-198 (2006).

8. Parrenin, F. et al. Synchronous change of atmospheric $\mathrm{CO}_{2}$ and Antarctic temperature during the last deglacial warming. Science 339, 1060-1063 (2013),

9. Nicolas, J. P. \& Bromwich, D. H. Climate of West Antarctica and influence of marine air intrusions. J. Clim. 24, 49-67 (2011).

10. Noone, D. \& Simmonds, I. Sea ice control of water isotope transport to Antarctica and implications for ice core interpretation. J. Geophys. Res. 109, D07105 (2004).

11. Steig, E. J. et al. in The West Antarctic Ice Sheet: Behavior and Environment Vol. 77 (eds Alley, R. \& Bindschadler, R.) 75-90 (American Geophysical Union, 2001).

12. Svensson, A. etal. A60,000 year Greenland stratigraphic ice core chronology. Clim. Past 4, 47-57 (2008).

13. Steig, E. J. et al. Recent climate and ice-sheet changes in West Antarctica compared with the past 2,000 years. Nature Geosci. 6, 372-375 (2013).

14. Stenni, B. et al. Expression of the bipolar see-saw in Antarctic climate records during the last deglaciation. Nature Geosci. 4, 46-49 (2011).

15. Hammer, C. U., Clausen, H. B. \& Langway, C. C. 50,000 years of recorded global volcanism. Clim. Change 35, 1-15 (1997).

16. Schwander, J. et al. A tentative chronology for the EPICA Dome Concordia ice core. Geophys. Res. Lett. 28, 4243-4246 (2001)

17. Wolff, E. W., Rankin, A. M. \& Rothlisberger, R. An ice core indicator of Antarctic sea ice production? Geophys. Res. Lett. 30, 2158 (2003).

18. Holland, P. R. \& Kwok, R. Wind-driven trends in Antarctic sea-ice drift. Nature Geosci. 5, 872-875 (2012).

19. Anderson, R. F. et al. Wind-driven upwelling in the Southern Ocean and the deglacial rise in atmospheric $\mathrm{CO}_{2}$. Science $323,1443-1448$ (2009).

20. Monnin, E. et al. Atmospheric $\mathrm{CO}_{2}$ concentrations over the last glacial termination. Science 291, 112-114 (2001).

21. Toggweiler, J. R., Russell, J. L. \& Carson, S. R. Midlatitude westerlies, atmospheric $\mathrm{CO} 2$, and climate change during the ice ages. Paleoceanography 21, PA2005 (2006).

22. Lee, S. Y., Chiang, J. C. H., Matsumoto, K. \& Tokos, K. S. Southern Ocean wind response to North Atlantic cooling and the rise in atmospheric $\mathrm{CO}_{2}$ : modeling perspective and paleoceanographic implications. Paleoceanography 26, PA1214 (2011).

23. Collins, L. G., Pike, J., Allen, C. S. \& Hodgson, D. A. High-resolution reconstruction of southwest Atlantic sea-ice and its role in the carbon cycle during marine isotope stages 3 and 2. Paleoceanography 27, PA3217 (2012).

24. Roeckner, E. et al. The Atmospheric General Circulation Model ECHAM-4: Model Description and Simulation of Present-Day Climate. Report No. 21890 (Max-PlanckInstitut für Meteorologie, 1996).

25. Braconnot, P. etal. Results of PMIP2 coupled simulations of the Mid-Holocene and Last Glacial Maximum - Part 1: experiments and large-scale features. Clim. Past 3, 261-277 (2007).

26. Huybers, P. Early Pleistocene glacial cycles and the integrated summer insolation forcing. Science 313, 508-511 (2006).

27. Pedro, J. B. et al. The last deglaciation: timing the bipolar seesaw. Clim. Past 7, 671-683 (2011).

28. Brook, E. J. et al. Timing of millennial-scale climate change at Siple Dome, West Antarctica, during the last glacial period. Quat. Sci. Rev. 24, 1333-1343 (2005).

29. Blunier, T. \& Brook, E. J. Timing of millennial-scale climate change in Antarctica and Greenland during the last glacial period. Science 291, 109-112 (2001).

30. Petit, J. R. etal. Climate and atmospheric history of the past 420,000 years from the Vostok ice core, Antarctica. Nature 399, 429-436 (1999).

31. Lemieux-Dudon, B. et al. Consistent dating for Antarctic and Greenland ice cores. Quat. Sci. Rev. 29, 8-20 (2010).

Supplementary Information is available in the online version of the paper.

Acknowledgements This work was supported by US National Science Foundation (NSF). The authors appreciate the support of the WAIS Divide Science Coordination Office (M. Twickler and J. Souney) for the collection and distribution of the WAIS Divide ice core; Ice Drilling and Design and Operations (K. Dahnert) for drilling; the National Ice Core Laboratory (B. Bencivengo) for curating the core; Raytheon Polar Services (M. Kippenhan) for logistics support in Antarctica; and the 109th New York Air National Guard for airlift in Antarctica. We also thank C. Buizert and S. Marcott for discussions. The following individual NSF grants supported this work: 0944197 (E.D.W.,

H. Conway); 1043092, 0537930 (E.J.S.); 0944348, 0944191, 0440817, 0440819, 0230396 (K.C.T.); 0538427,0839093 (J.R.M.); 1043518 (E.J.B.); 1043500 (T.S.); 05379853,1043167 (J.W.C.W.); 1043528,0539578 (R.B.A.); 0539232 (K.M.C., G.D.C.); 1103403 (R.L.E., H. Conway); 0739780 (R.E); 0637211 (G.H.); 0538553 0839066 (J.C.-D.), 0538657,1043421 (J.P.S.); 1043313 (M.K.S.); 0801490 (G.J.W) Other support came from a NASA NESSF award (T.J.F.), the USGS Climate and Land Use Change Program (G.D.C., J.J.F.), the National Natural Science Foundation of China (41230524 to H. Cheng) and the Singapore National Research Foundation (NRFF2011-08 to X.W.). 
Author Contributions The manuscript was written by T J.F, EJ.S. and B.R.M. K.C.T. organized the WAIS Divide Project. T.J.F., K.C.T and T.J.P. made the electrical measurements and developed the electrical timescale with K.C.M. E.J.S., J.W.C.W., A.J.S., P.N., B.H.V. and S.W.S. measured the stable-isotope record. J.R.M., M.S., O.J.M. and R.E. developed the chemistry timescale and measured Na. E.J.B., T.S., L.E.M., J.S.E. and J.E.L. made the methane measurements. G.D.C. and K.M.C. measured the borehole temperature profile. J.C.-D. and D.F. provided an independent timescale for the brittle ice. Q.D., S.W.S. and E.J.S. performed the climate modelling. T.J.F., E.D.W., H. Conway and K.M.C. performed the ice-flow modelling to determine the accumulation rate. H. Cheng, R.L.E., X.W., J.P.S. and T.J.F. made comparisons with the Hulu cave timescale. M.K.S., J.J.F., J.M.F., D.E.V. and R.B.A. examined the physical properties of the core. W.M. J.J. and N.M. designed the drill. G.H. designed core-processing techniques. A.J.O. B.H.V. D.E.V., K.C.T., T.J.P. and G.J.W. led collection and processing of the core in the field.

Author Information Reprints and permissions information is available at www.nature.com/reprints. The authors declare no competing financial interests. Readers are welcome to comment on the online version of the paper. Correspondence and requests for materials should be addressed to T.J.F. (tjfudge@uw.edu).

WAIS Divide Project Members T. J. Fudge ${ }^{1}$, Eric J. Steig ${ }^{1,2}$, Bradley R. Markle ${ }^{1}$, Spruce W. Schoenemann ${ }^{1}$, Qinghua Ding ${ }^{1,2}$, Kendrick C. Taylor ${ }^{3}$, Joseph R. McConnell ${ }^{3}$ Edward J. Brook ${ }^{4}$, Todd Sowers ${ }^{5}$, James W. C. White ${ }^{6,7}$, Richard B. Alley ${ }^{5,8}$, Hai Cheng ${ }^{9,10}$, Gary D. Clow ${ }^{11}$, Jihong Cole-Dai ${ }^{12}$, Howard Conway ${ }^{1}$, Kurt M. Cuffey ${ }^{13}$, Jon S. Edwards ${ }^{4}$, R. Lawrence Edwards ${ }^{10}$, Ross Edwards ${ }^{14}$, John M. Fegyveresi ${ }^{5,8}$, David Ferris $^{12}$, Joan J. Fitzpatrick ${ }^{15}$, Jay Johnson ${ }^{16}$, Geoffrey Hargreaves ${ }^{17}$, James E. Lee ${ }^{4}$, Olivia J. Maselli ${ }^{3}$, William Mason ${ }^{18}$, Kenneth C. McGwire ${ }^{3}$, Logan E. Mitchell ${ }^{4}$, Nicolai Mortensen ${ }^{16}$, Peter Neff ${ }^{1,19}$, Anais J. Orsi ${ }^{20}$, Trevor J. Popp ${ }^{21}$, Andrew J. Schauer ${ }^{1}$,
Jeffrey P. Severinghaus ${ }^{20}$, Michael Sig| ${ }^{3}$, Matthew K. Spencer ${ }^{22}$, Bruce H. Vaughn ${ }^{7}$, Donald E. Voigt ${ }^{5,8}$, Edwin D. Waddington ${ }^{1}$, Xianfeng Wang ${ }^{23}$ \& Gifford J. Wong ${ }^{24}$

Affiliations for participants: ${ }^{1}$ Department of Earth and Space Sciences, University of Washington, Seattle, Washington 98195, USA. ${ }^{2}$ Quaternary Research Center, University of Washington, Seattle, Washington 98195, USA. ${ }^{3}$ Desert Research Institute, Nevada System of Higher Education, Reno, Nevada 89512, USA. ${ }^{4}$ College of Earth, Ocean and Atmospheric Sciences Oregon State University, Corvallis, Oregon 97331, USA. ${ }^{5}$ Earth and Environmental Systems Institute, Pennsylvania State University, University Park, Pennsylvania 16802, USA. ${ }^{6}$ Department of Geological Sciences and Department of Environmental Studies, Boulder, Colorado 80309, USA. ${ }^{7}$ INSTAAR, University of Colorado, Boulder, Colorado 80309, USA. ${ }^{8}$ Department of Geosciences, Pennsylvania State University, University Park, Pennsylvania 16802, USA. ${ }^{9}$ Institute of Global Environmental Change, Xi'an Jiaotong University, Xi'an 710049, China. ${ }^{10}$ Department of Earth Sciences, University of Minnesota, Minneapolis, Minnesota 55455, USA. ${ }^{11}$ US Geological Survey, Geosciences and Environmental Change Science Center, Lakewood, Colorado 80225, USA. ${ }^{12}$ Department of Chemistry and Biochemistry, South Dakota State University, Brookings, South Dakota 57007, USA. ${ }^{13}$ Department of Geography, University of California-Berkeley, Berkeley 94720, USA. ${ }^{14}$ Department of Imaging and Applied Physics, Curtin University, Perth, Western Australia 6102, Australia. ${ }^{15}$ US Geological Survey, Denver, Colorado 80225, USA. ${ }^{16}$ Ice Drilling Design and Operations, Space Science Engineering Center, University of Wisconsin-Madison, Madison, Wisconsin 53706, USA ${ }^{17}$ US Geologic Survey, National Ice Core Laboratory, Denver, Colorado 80225, USA. ${ }^{18}$ EMECH Designs, Brooklyn, Wisconsin 53521, USA. ${ }^{19}$ Antarctic Research Centre, Victoria University of Wellington, Wellington 6012, New Zealand. ${ }^{20}$ Scripps Institution of Oceanography, University of California, San Diego, La Jolla, California 92037, USA.

${ }^{21}$ Centre for Ice and Climate, Niels Bohr Institute, University of Copenhagen, Juliane Maries Vej 30, 2100 Copenhagen, Denmark. ${ }^{22}$ Department of Geology and Physics, Lake Superior State University, Sault Ste Marie, Michigan 49783, USA. ${ }^{23}$ Earth Observatory of Singapore, Nanyang Technological University, Singapore 639798. ${ }^{24}$ Department of Earth Sciences, Dartmouth College, Hanover, New Hampshire 03755, USA. 


\section{METHODS}

Stable-isotope measurements of ice. Water isotope analyses were by laser spectroscopy ${ }^{32}$ at the University of Washington. Values of $\delta^{18} \mathrm{O}$ represent the deviation from Vienna Standard Mean Ocean Water (VSMOW) normalized ${ }^{11}$ to the VSMOW-SLAP standards and reported in per mil (\%o). The precision of the measurements is better than $0.1 \%$. The data have not been corrected for advection, elevation, or mean seawater $\delta^{18} \mathrm{O}$.

Accumulation rates. The accumulation-rate record was derived independently from the stable-isotope record using an ice-flow model to calculate the thinning function. We use a transient one-dimensional ice-flow model to compute the vertical-velocity profile:

$$
w(z)=-(\dot{b}-\dot{m}-\dot{H}) \psi(z)-\dot{m}-\left(\frac{\rho_{\mathrm{i}}}{\rho(z)}-1\right) \dot{b}
$$

Here $z$ is the height above the bed, $\dot{b}$ is the accumulation rate, $\dot{m}$ is the melt rate, $\dot{H}$ is the rate of ice-thickness change, $\rho_{\mathrm{i}}$ is the density of ice, $\rho(z)$ is the density profile and $\psi(z)$ is the vertical velocity shape function computed as

$$
\begin{gathered}
\psi(z)=\frac{\left(f_{\mathrm{B}} z+(1 / 2)\left(1-f_{\mathrm{B}}\right)\left(z^{2} / h\right)\right)}{\left(H-(h / 2)\left(1-f_{\mathrm{B}}\right)\right)} \quad \text { for } h \geq z>0 \\
\psi(z)=\frac{\left(z-(h / 2)\left(1-f_{\mathrm{B}}\right)\right)}{\left(H-(h / 2)\left(1-f_{\mathrm{B}}\right)\right)} \quad \text { for } H \geq z>h
\end{gathered}
$$

following ref. 33. Here $h$ is the distance above bedrock of the Dansgaard-Johnsen ${ }^{34}$ kink height, $f_{\mathrm{B}}$ is the fraction of the horizontal surface velocity due to sliding over the bed and $H$ is the ice thickness. Firn compaction is incorporated through the rightmost term in equation (1) and assumes a density profile that does not vary with time.

A constant ice thickness was specified because the thickness change near the divide was probably small $(\sim 100 \mathrm{~m})$ and the timing of thickening and thinning is not well constrained; a 100-m thickness change would alter the inferred accumulation rate by $\sim 3 \%$. A constant basal melt rate of $1 \mathrm{~cm} \mathrm{yr}^{-1}$ and non-divide flow conditions, represented by a Dansgaard-Johnsen kink height of $0.2 \mathrm{H}$, were assumed. We also prescribed a sliding fraction of 0.5 of the surface velocity, which approximates effects of both basal sliding and enhanced shear near the bed, neither of which is well constrained. To assess the possible range of inferred accumulation rates, we also used sliding fractions of 0.15 and 0.9 (Supplementary Fig. 2). The inferred accumulation rate was only slightly affected for the Holocene part of the record but differed by up to $16 \%$ for the oldest part of the record ( $29.6 \mathrm{kyr}$ ago). Because the thinning function varies smoothly, the uncertainty in the timing of the changes in accumulation rate is only weakly affected by the uncertainty in the magnitude of the accumulation rate. The main uncertainty in identifying the timing of accumulation rate changes is the uncertainty in the timescale itself. During the deglacial transition, the uncertainty in the interpretation is estimated at $8 \%$. The yellow shading in Fig. 3 shows this uncertainty.

WDC06A-7 timescale. The WDC06A-7 timescale is based on high-resolution $(<1 \mathrm{~cm})$ measurements of sulphur, sodium, black carbon and electrical conductivity (ECM) above $577 \mathrm{~m}$ (2,358 yr before present (BP; AD 1950); ref. 35). Below 577 m, WDC06A-7 is based primarily on electrical measurements: di-electrical profiling was used for the brittle ice from 577 to $1,300 \mathrm{~m}$ (to $6,063 \mathrm{yr} \mathrm{BP}$ ). Alternating-current ECM measurements were used from 1,300 to $1,955 \mathrm{~m}$ (to $11,589 \mathrm{yr} \mathrm{BP}$ ) and both alternating-current and direct-current ECM measurements were used below $1,955 \mathrm{~m}$. The interpretation was stopped at $2,800 \mathrm{~m}$ because the expression of annual layers becomes less consistent, suggesting that all years may not be easily recognized.

The upper $577 \mathrm{~m}$ of the timescale has been compared with volcanic horizons dated on multiple other timescales ${ }^{35}$; the uncertainty at $2,358 \mathrm{yr}$ вP is $\pm 19 \mathrm{yr}$. For the remainder of the timescale, we assigned an uncertainty based on a qualitative assessment of the clarity of the annual layers. For ice from 577 to $2,020 \mathrm{~m} \mathrm{(2-12} \mathrm{kyr}$ ago), we estimated a $2 \%$ uncertainty based on comparisons between the ECM and chemical $\left(\mathrm{Na}, \mathrm{SO}_{4}\right)$ interpretations between 577 and $1,300 \mathrm{~m}$, which agreed to within 1\% (Supplementary Fig. 4). The estimated uncertainty increased during the deglacial transition owing to both thinner layers and a less pronounced seasonal cycle. We compared the annual-layer interpretation of the ECM records in an 800 -yr overlap section (1,940-2,020-m depth, corresponding to 11.4-12.2 kyr ago) with various high-resolution chemistry records (sodium and sulphur). We found overall good agreement (19yr more in the ECM-only interpretation) but did observe a tendency for the ECM record to 'split' one annual peak into two small peaks. We used this knowledge in the annual-layer interpretation of the ECM record. We increased the uncertainty to $4 \%$ between 2,020 and $2,300 \mathrm{~m}(12.2-$ $15.5 \mathrm{kyr}$ ago) and to $8 \%$ between 2,300 and 2,500 $\mathrm{m}$ (15.5-20 kyr ago). The glacial period had a stronger annual-layer signal than the transition, and we estimate a $6 \%$ uncertainty for the rest of the glacial. The 150-yr acid deposition event, first identified in the Byrd ice core ${ }^{15}$, was found in WDC at depths of 2,421.75 to $2,427.25 \mathrm{~m}$. Because there is consistently high conductance without a clear annual signal, we used the average annual layer thickness of the $10 \mathrm{~m}$ above and below this section to determine the number of years within it. There are periods of detectable annual variations within this depth range, and they have approximately the same annual-layer thickness as the $10-\mathrm{m}$ averages. A $10 \%$ uncertainty was assumed.

We assess the accuracy of WDC06A-7 by comparing it with two high-precision timescales: GICC05 and a new speleothem timescale from Hulu Cave. Because the age of the gas at a given depth is less than that of the ice surrounding it, we first need to calculate the age offset ( $\Delta$ age). We use the inferred accumulation rates and surface temperatures estimated from the $\delta^{18} \mathrm{O}$ record constrained by the borehole temperature profile (Supplementary Information) in a steady-state firn-densification model ${ }^{36}$. The model is well-suited to WDC because it was developed using data from modern ice-core sites that span the full range of past WDC temperatures and accumulation rates. We calculate $\Delta$ age using 200-yr smoothed histories of surface temperature and accumulation rate, a surface density of $370 \mathrm{~kg} \mathrm{~m}^{-3}$ and a close-off density of $810 \mathrm{~kg} \mathrm{~m}^{-3}$ (Supplementary Fig. 5a). The calculated present-day $\Delta$ age is $210 \mathrm{yr}$, which is similar to the value, $205 \mathrm{yr}$, measured for $\mathrm{WDC}^{37}$. The steady-state model is acceptable for WDC because the surface temperature and accumulation rate vary more slowly than in Greenland. Because our primary purpose is to assess the accuracy of the WDC06A-7 timescale, calculation of $\Delta$ age to better than a few decades is not necessary. The $\Delta$ age uncertainty between 15 and $11 \mathrm{kyr}$ ago is estimated to be $100 \mathrm{yr}$. The $\Delta$ age uncertainty is estimated to be $150 \mathrm{yr}$ for times before $20 \mathrm{kyr}$ ago because of the colder temperatures and lower and less certain accumulation rates.

Because methane is well mixed in the atmosphere and should have identical features in both hemispheres, we use atmospheric methane measurements from WDC and the Greenland composite methane record ${ }^{33}$ to compare WDC06A-7 and GICC05 at six times. The age differences are summarized in Supplementary Fig. 6 and the correlation and $\Delta$ age uncertainties are shown in Supplementary Table 1. In Greenland, methane and $\delta^{18} \mathrm{O}$ changes are nearly synchronous ${ }^{38-40}$ and we therefore assume no $\Delta$ age uncertainty in the Greenland gas timescale at times of abrupt change. An exception is at $24 \mathrm{kyr}$ ago (Dansgaard-Oeschger event 2), when methane and $\delta^{18} \mathrm{O}$ changes do not seem to be synchronous. We estimate the correlation uncertainty from the agreement of the methane records in Supplementary Fig. 5.

Speleothems can be radiometrically dated with U/Th and have smaller absolute age uncertainties than do annually resolved timescales in the glacial period ${ }^{37}$. Records of speleothem $\delta^{18} \mathrm{O}$ show many abrupt changes that have been tied to the Greenland climate record ${ }^{41,42}$. However, the physical link between $\delta^{18} \mathrm{O}$ variations in the caves and methane variations is not fully understood. Therefore, there is an additional and unknown correlation uncertainty in these comparisons. We compare WDC06A-7 with the new record from Hulu Cave, China, which is the best-dated speleothem record during this time interval. Comparisons can be made at only three times; our best estimate of the age differences is $100 \mathrm{yr}$ or less.

The EDC timescale can be compared with the WDC06A-7 at a $\sim 150$-yr-long acid deposition event ${ }^{15,16}$. The two timescales agree within $100 \mathrm{yr}$, and we therefore do not adjust either timescale. The EDML timescale has been synchronized with the EDC timescale using sulphate matches ${ }^{43}$. The sulphate match that occurs during the 150-yr acid deposition event is marked in Fig. 2.

Sea-salt sodium measurements. Sea-salt sodium $(\mathrm{ssNa})$ is the amount of $\mathrm{Na}$ that is of marine origin. The Na record was measured at the Trace Chemistry Laboratory at the Desert Research Institute. Na is one of many elements measured on the continuous-flow analysis system, which is coupled to two inductively coupled plasma mass spectrometers. The effective sampling resolution is $\sim 1 \mathrm{~cm}$. Details of the analytical set-up are described elsewhere ${ }^{35,44-47}$. Sea-salt $\mathrm{Na}$ is calculated assuming $\mathrm{Na} / \mathrm{Ca}$ mass ratios of 26.3 for marine aerosols and 0.562 for average crust composition $^{48}$. Sea-salt $\mathrm{Na}$ can be influenced by volcanic activity if the ratio of $\mathrm{Na}$ to Ca is different from the sea water and crustal ratios; the spike $20 \mathrm{kyr}$ ago is part of an Na-rich but $\mathrm{Ca}$-poor volcanic event. We present ssNa concentration in the main text instead of ssNa flux because wet deposition dominates at higher accumulation rates $^{49}$. For comparison, the ssNa flux is shown in Supplementary Fig. 7.

Methane measurements. The methane concentration was measured in discrete samples at Oregon State University (OSU) and Pennsylvania State University (PSU) using automated melt-refreeze extraction and gas chromatography, with final concentration values reported on the NOAA04 concentration scale ${ }^{50}$. OSU data are corrected for gravitational fractionation, solubility and blanks as described in ref. 37. The gravitation fractionation correction assumes that $\delta^{15} \mathrm{~N}$ of $\mathrm{N}_{2}$ is $0.3 \%$, a value based on late-Holocene measurements.

PSU methods were modelled on the basis of the OSU melt-refreeze system. The major difference between the OSU and PSU methods is the extraction cylinders; glass at OSU and stainless steel at PSU. Using stainless steel cylinders carries the 
added problem of a blank associated with $\mathrm{CH}_{4}$ outgassing, which we have estimated to be $19 \pm 8$ p.p.b. We have used a calculation similar to that derived in ref. 37, to estimate the amount of $\mathrm{CH}_{4}$ left in the vessel after refreezing; we verified this using artificially degassed ice samples over which standard air was introduced and processed. These results indicate a $3.8 \%$ reduction in the measured headspace $\mathrm{CH}_{4}$ value relative to the original trapped air, owing to solubility effects. The constant solubility and blank corrections were applied to all PSU data. In general, replicate samples from each depth were run on separate days to ensure that the final averaged data were not aliased by day-to-day instrument drifts. The average difference between replicate analyses of 1,316 individual depths run over $4 \mathrm{yr}$ was $7 \pm 8$ p.p.b. $(1 \sigma)$. Finally, the PSU data were also corrected for gravitational fractionation by assuming that $\delta^{15} \mathrm{~N}$ of $\mathrm{N}_{2}$ is $0.3 \%$ throughout.

To ensure that the PSU and $\mathrm{OSU} \mathrm{CH}_{4}$ data sets can be accurately merged into a single record, we performed an inter-calibration exercise involving a $100-\mathrm{m} \mathrm{sec}-$ tion of the WDC06A core (400-500 m) where both labs sampled for $\mathrm{CH}_{4}$ every $2 \mathrm{~m}$. By interpolating the OSU data to compare with the PSU data, we determined the average difference between the two labs over this $100 \mathrm{~m}$ interval to be $0.2 \pm 9.9$ p.p.b. $(1 \sigma)$. This result implies that we can merge $\mathrm{CH}_{4}$ data from the two labs without correcting for inter-laboratory offsets.

Wilcoxon rank-sum test. Initial inspection of the WDC isotope record showed that warming was pulsed. We applied a sliding Wilcoxon rank-sum statistical test ${ }^{51}$ to identify periods of significant change. A figure of the $P$ values, for each individual Wilcoxon rank-sum test, is shown in Supplementary Fig. 8. A dashed line indicates the effective critical $P$ value. Insignificant $P$ values are plotted in grey, and significant $P$ values are plotted in colours that correspond to timespan (block size) as in Fig. 2. The Wilcoxon rank-sum test makes no assumption of normality within the data and has been shown to be robust when used in windowing algorithms for the identification of periods of significant change in climate data ${ }^{52}$. Our windowing algorithm can also be applied using the more common Student's $t$-test. Though parametric, such an implementation has the benefit of a well-established method for correcting the degrees of freedom for autocorrelation within the data ${ }^{53}$. Applying either statistical test, we identify nearly identical periods of significant change in the data sets.

Climate modelling. To assess the effects of changing sea-ice conditions on precipitation-weighted $\delta^{18} \mathrm{O}$ in Antarctica, we used the ECHAM4.6 climate model $^{24}$, implemented with the water isotope module ${ }^{54}$. Model simulations used a horizontal resolution of T42 $\left(2.8^{\circ}\right.$ latitude by $2.8^{\circ}$ longitude $)$ with 19 vertical levels. The ECHAM4.6 model has been shown to reproduce Antarctic conditions realistically in the modern climate ${ }^{13,55}$. We used the sea surface temperatures from the PMIP2 fully coupled model experiments ${ }^{25}$ for LGM conditions $\sim 21 \mathrm{kyr}$ ago. Those sea surface temperatures are prescribed as a model boundary condition for the atmospheric model runs with ECHAM4.6. We used a modern Antarctic icesheet configuration because the LGM configuration remains poorly known.

Model experiments were designed to test the sensitivity of $\delta^{18} \mathrm{O}$ to changes in sea-ice extent. In the control experiment, sea ice forms at $-1.7^{\circ} \mathrm{C}$ and the model grid cell is set to $100 \%$ concentration below this threshold. The latitude of sea-ice coverage is decreased by lowering the ocean surface temperature threshold at which sea ice forms in the model. For the run with decreased sea ice, the freezing point was lowered from -1.7 to $-3.7^{\circ} \mathrm{C}$. The amount of sea-ice reduction is not zonally uniform around Antarctica because of asymmetric gradients in the prescribed sea surface temperature. We note that model sea surface temperatures do not change whether model sea ice is present or not. Newly formed open water in the run with reduced sea ice is below the freezing point.
Integrated insolation. We calculate integrated annual insolation at latitude $65^{\circ} \mathrm{S}$ following the tables prepared in ref. 26 . We also calculate integrated 'summer' and 'winter' insolation using a cut-off of $275 \mathrm{~W} \mathrm{~m}^{-2}$ (ref. 26; Supplementary Fig. 10).

32. Crosson, E. R. A cavity ring-down analyzer for measuring atmospheric levels of methane, carbon dioxide, and water vapor. Appl. Phys. B 92, 403-408 (2008).

33. Dahl-Jensen, D., Gundestrup, N., Gogineni, S. P. \& Miller, H. Basal melt at NorthGRIP modeled from borehole, ice-core and radio-echo sounder observations. Ann. Glaciol. 37, 207-212 (2003).

34. Dansgaard, W. \& Johnsen, S. J. A flow model and a time scale for the ice core from Camp Century, Greenland. J. Glaciol. 8, 215-223 (1969).

35. Sigl, M. et al. A new bipolar ice core record of volcanism from WAIS Divide and NEEM and implications for climate forcing of the last 2000 years. J. Geophys. Res. 18, 1151-1169 (2013)

36. Herron, M. M. \& Langway, C. C. Firn densification: an empirical model. J. Glaciol. 25 , 373-385 (1980).

37. Mitchell, L. E., Brook, E. J., Sowers, T., McConnell, J. R. \& Taylor, K. Multidecadal variability of atmospheric methane, 1000-1800 CE. J. Geophys. Res. 116, G02007 (2011).

38. Huber, C. et al. Evidence for molecular size dependent gas fractionation in firn air derived from noble gases, oxygen, and nitrogen measurements. Earth Planet. Sci. Lett. 243, 61-73 (2006)

39. Kobashi, T., Severinghaus, J. P., Brook, E. J., Barnola, J. M. \& Grachev, A. M. Precise timing and characterization of abrupt climate change 8200 years ago from air trapped in polar ice. Quat Sci. Rev. 26, 1212-1222 (2007).

40. Severinghaus, J. P., Sowers, T., Brook, E. J., Alley, R. B. \& Bender, M. L. Timing of abrupt climate change at the end of the Younger Dryas interval from thermally fractionated gases in polar ice. Nature 391, 141-146 (1998).

41. Fleitmann, D. etal. Timing and climatic impact of Greenland interstadials recorded in stalagmites from northern Turkey. Geophys. Res. Lett. 36, L19707 (2009).

42. Cheng, H. et al. Ice age terminations. Science 326, 248-252 (2009).

43. Ruth, U. et al. "EDML1": a chronology for the EPICA deep ice core from Dronning Maud Land, Antarctica, over the last 150,000 years. Clim. Past 3, 475-484 (2007).

44. Bisiaux, M. M. et al. Changes in black carbon deposition to Antarctica from two high-resolution ice core records, 1850-2000 AD. Atmos. Chem. Phys. 12 4107-4115 (2012)

45. McConnell, J. R. Continuous ice-core chemical analyses using inductively coupled plasma mass spectrometry. Environ. Sci. Technol. 36, 7-11 (2002).

46. McConnell, J. R. et al. 20th-century industrial black carbon emissions altered arctic climate forcing. Science 317, 1381-1384 (2007).

47. Pasteris, D. R., McConnell, J. R. \& Edwards, R. High-resolution, continuous method for measurement of acidity in ice cores. Environ. Sci. Technol. 46, 1659-1666 (2012).

48. Röthlisberger, R, Crosta, X, Abram, N. J, Armand, L. \& Wolff, E. W. Potential and limitations of marine and ice core sea ice proxies: an example from the Indian Ocean sector. Quat. Sci. Rev. 29, 296-302 (2010).

49. Alley, R. B. et al. Changes in continental and sea-salt atmospheric loadings in central Greenland during the most recent deglaciation: model-based estimates. J. Glaciol. 41, 503-514 (1995)

50. Dlugokencky, E. J. et al. Conversion of NOAA atmospheric dry air $\mathrm{CH}_{4}$ mole fractions to a gravimetrically prepared standard scale. J. Geophys. Res. 110, D18306 (2005).

51. Wilcoxon, F. Individual comparisons by ranking methods. Biom. Bull. 1, 80-83 (1945).

52. Mauget, S. A. Intra- to multidecadal climate variability over the continental United States: 1932-99. J. Clim. 16, 2215-2231 (2003).

53. Bretherton, C. S., Widmann, M., Dymnikov, V. P., Wallace, J. M. \& Blade, I. The effective number of spatial degrees of freedom of a time-varying field. J. Clim. 12, 1990-2009 (1999)

54. Hoffmann, G., Werner, M. \& Heimann, M. Water isotope module of the ECHAM atmospheric general circulation model: a study on timescales from days to several years. J. Geophys. Res. 103, 16871-16896 (1998).

55. Ding, Q. H., Steig, E. J., Battisti, D. S. \& Kuttel, M. Winter warming in West Antarctica caused by central tropical Pacific warming. Nature Geosci. 4, 398-403 (2011). 